\title{
Erratum to: Organic-inorganic hybrid melting gels
}

\author{
Lisa C. Klein · Andrei Jitianu
}

Published online: 12 February 2011

(C) Springer Science+Business Media, LLC 2011

\begin{abstract}
Melting gels are a class of organically modified silica gels that are rigid at room temperature, flow at temperature $\mathrm{T} 1$ and consolidate at temperature $\mathrm{T} 2$ (T2 $>\mathrm{T} 1$ ), when crosslinking is complete. The process of (a) softening, (b) becoming rigid and (c) re-softening can be repeated many times. Mixtures of mono-substituted alkoxysilanes and di-substituted alkoxysilanes have been studied in a systematic way to identify suitable melting gel compositions. The mixtures and the resulting melting gels have been characterized for their softening temperatures and consolidation temperatures. With an interest in using these materials for sealing microelectronics, their physical properties have been measured.
\end{abstract}

Keywords Melting gels - Polysiloxanes · Organic-inorganic hybrids · Glass transition temperature $\cdot$ Low-k dielectric

The online version of the original article can be found under doi: 10.1007/s10971-010-2219-4.

Due to a production error, this article was previously published in the July 2010 issue of this journal (Vol. 55, No. 1). It is reprinted here in its entirety.

L. C. Klein $(\bowtie)$

Department of Materials Science and Engineering, Rutgers University, 607 Taylor Road, Piscataway, NJ 08854, USA

e-mail: licklein@ rci.rutgers.edu

\section{A. Jitianu}

Department of Chemistry, Lehman College, City University of New York, Davis Hall, 250 Bedford Park Boulevard West, Bronx, NY 10468, USA

\section{Introduction}

\subsection{Introduction to "melting gels"}

Ordinarily, the outcome of the sol-gel process with the precursor tetraethylorthosilicate (TEOS) is a 3-dimensional network. By hydrolysis and poly-condensation, the TEOS, with 4 identical groups attached to $\mathrm{Si}$, undergoes reactions according to $\mathrm{pH}$ and steric effects. However, the 4 identical groups can be changed to, for example, 3 identical groups and one group with a direct $\mathrm{Si}-\mathrm{C}$ bond. While the ethoxy groups are hydrolytically reactive, the substituted group, for example, methyl, does not hydrolyze.

Figure 1 is a schematic of the number of reactive groups (NRG), as the ethoxy group on TEOS is substituted once by methyl, and twice by methyl. Substituting groups, which have been studied, include methyl, ethyl, phenyl, vinyl and many others [1]. Vinyl groups have been used because it is possible to polymerize the vinyl groups with UV irradiation.

In one of the cases, which will be described in detail, it is possible to prepare silica-based hybrid gels that are rigid at room temperature, but soften and flow repeatedly around $110^{\circ} \mathrm{C}$. While the softening behavior has been called melting, it is not melting in a thermodynamic sense [2]. At the same time, it is not thixotropic behavior either, because the material cannot be caused to flow by shearing. Instead, the ability to flow is an indication that the material is not sufficiently cross-linked. In fact, some of the hybrid glasses show glass transition behavior at temperatures below $0^{\circ} \mathrm{C}$. However, once these so-called melting gels have been consolidated at around $160^{\circ} \mathrm{C}$, they no longer show the ability to soften. The consolidation treatment increases the degree of cross-linking in the gel to a point where the network is permanently rigid [3-5]. 
Fig. 1 Schematics showing number of reactive groups (NRG)<smiles>CCO[Si](OCC)(OCC)OCC</smiles>

NRG<smiles>CCO[Si](C)(OCC)OCC</smiles>

3<smiles>CCO[Si](C)(C)OCC</smiles>

2
Mixtures of di-substituted and mono-substituted alkoxysilanes can produce so-called melting gels with a range of softening behaviors and a range of temperatures where the gel flows. As mentioned, the substituted groups can be methyl groups or phenyl groups, as well as others. The size and polarity of the groups influences the properties. The properties of these mixtures are the subject of this review.

\subsection{Property requirements for low $\mathrm{k}$ materials in integrated circuits}

Many of the desired characteristics of so-called "low k materials" in microelectronics can be satisfied by melting gels [6]. For simple metal-oxide semiconductor field effect transistors (MOSFET), the low-k materials should be structurally uniform, have low dielectric constant $(k \sim 2)$, low dielectric loss, high hardness, high adhesion strength, thermal stability, and low moisture absorption [7]. Because of the network structure in organically modified silica melting gels, the structural uniformity and hardness can be achieved. Also, the fact that $\mathrm{SiO}_{2}$ has a low $\mathrm{k}$ by itself means that the dielectric constant of the melting gel can be close to 2 with the proper amount of organic and possibly some closed porosity [8]. In addition, the silica content of the hybrid gives the low $\mathrm{k}$ material thermal stability. Melting gels have low viscosity at their softening temperature, so they can be applied by spin coating. The coatings show good adhesion to silicon substrates. In the limited testing so far, the melting gels show very low vapor transport values [3]. For all of these reasons, melting gels are interesting materials to consider for multilevel interconnect structures. Further work is needed to characterize electrical properties, such as leakage current, and chemical properties, such as etch selectivity.

\subsection{Background of "ORMOSILs"}

Hybrid organic-inorganic sol-gel materials containing silica were first called "ORMOSILs" in 1984 [9]. Since then the number of hybrid organic-inorganic combinations has increased rapidly [1]. Generally, organic-inorganic materials are classified in two broad categories: materials where the organic and inorganic components are embedded one within the other and display weak bonds (Class I), and materials where there are strong covalent bonds between the inorganic and organic components (Class II) [10]. In Class II, a common type of precursor is organoalkoxysilanes with general formula $\mathrm{R}_{n}{ }^{\prime}-\mathrm{Si}(\mathrm{OR})_{4-n}$. The result of hydrolysis and poly-condensation of these precursors are organo-polysiloxanes, which have desirable properties such as hydrophobicity, corrosion protection, low dielectric constants or good scratch resistance [11].

A common precursor for Class II hybrids is methyltriethoxysilane (MTES), $\mathrm{CH}_{3} \mathrm{Si}\left(\mathrm{OC}_{2} \mathrm{H}_{5}\right)_{3}$. MTES together with tetraethoxysilane (TEOS) leads to hybrid thin films [12]. When TEOS and MTES are mixed together and hydrolyzed with ammonia catalyst, it is found that condensation is faster than hydrolysis [13, 14]. The retention of the methyl groups in the films reduces tension and lessens cracking. Overall, the order of reactivity for the precursors increases from mono-substituted (MTES) to non-substituted (TEOS) to di-substituted (dimethyldiethoxysilane, DMDES) [15].

More complicated ORMOSILs are obtained by co-condensation of TEOS with MTES and vinyltriethoxysilane $[16,17]$ and 3 glycidoxy-propyltrimethoxysilane [17, 18]. Oxygen barrier coatings were achieved by using dielectric barrier discharge on vinyltriethoxysilane under ambient conditions [19]. Another approach to an oxygen barrier involved a hybrid layer with n-octyltriethoxysilane over an active layer that acts as an oxygen scavenger [20].

Other organic-inorganic coatings were developed for anti-graffiti, anti-adhesive and anti-static coatings, among others [21]. Since the refractive index and the thickness of hybrid coatings can be adjusted, waveguides based on phenyltriethoxysilane (PhTES), MTES and TEOS have been patterned by microfluidic lithography [22, 23]. Using a mixture of TEOS, MTES and DMDES, a planar integrated waveguide for water vapor sensing, was obtained by doping with Erytrosin B [24].

Another important feature of hybrid materials is the surface energy, which is reflected in its hydrophobicity or hydrophilicity. For example, a water-repelling surface has a contact angle greater than $90^{\circ}$ because of surface chemistry and roughness, which increases the effective surface area $[25,26]$. For silica-based hybrids, the affinity for water can be decreased by reducing the number of the vicinal $\mathrm{OH}$ groups [27]. Reducing the $\mathrm{OH}$ groups can be achieved by 
replacing them with hydrophobic groups such as methyl [28]. Fluorine is the most effective element for lowering the surface energy, resulting in decreasing contact angle in the order $-\mathrm{CF}_{3}>-\mathrm{CF}_{2} \mathrm{H}>-\mathrm{CF}_{2}->-\mathrm{CH}_{3}>-\mathrm{CH}_{2}-$ [26].

The mechanical properties of hybrid materials are relevant when coatings are designed to protect glass [29] or polycarbonate [30]. Hybrid films containing TEOS and MTES showed a decrease in hardness from 1.75 to 0.35 GPa as the MTES content increased [31]. The nature of the organic group bonded to the silica network has a large effect on hardness, for example, hybrids with methyl groups are up to 4 times harder than hybrids with phenyl groups [32]. In addition, hardness varies with synthesis conditions, such as the type and amount of catalyst, the amount of the solvent, and the temperature of heat treatment [33].

A special category of hybrid gels constitutes the socalled "melting gels" [2-4]. These hybrids have been developed to replace low melting temperature sealing glasses that melt around $600^{\circ} \mathrm{C}$. This temperature is too high for most electronic packaging, especially newer devices such as organic light emitting diodes (OLED). An early approach to "melting gels" involved preparing poly(benzyl-silsesquioxane) particles, which were deposited onto an indium-tin oxide (ITO) coated substrate by electrophoretic deposition. After heat treatment at very low temperatures, continuous thick transparent films were obtained [2]. Using a different approach with PhTES and DPhDES (diphenyldiethoxysilane), poly-silsesquioxanes were obtained that showed a low softening point. The first step involved hydrochloric acid, followed by a second step with ammonia to encourage condensation. Using a variety of analytical techniques, it was shown that the resulting molecular structure was three-dimensional, with the organic groups having weak bonds between molecular chains [33-35]. PhTES-DPhDES hybrids could be formed with or without ethanol as monodisperse particles, and the glass transition temperature of these hybrids varied with ratio of PhTES and DPhDES [36, 37].

\section{Experimental}

\subsection{Precursors for melting gels}

While the catalog of alkoxysilanes is almost limitless, the typical precursors are listed in Table 1. These include 4 pairs of mono-substituted and di-substituted alkoxysilanes, with the substitution being either methyl or phenyl, and the alkoxy group being ethoxy or methoxy. All of the precursors are readily available from catalogs such as Gelest (Morrisville, PA) and Sigma-Aldrich (Milwaukee, WI). Note that all of the precursors are liquids at room temperature, and all are described as reacting slowly with water at room temperature. Vinyltriethoxysilane and the unsubstituted precursors tetraethylorthosilicate and tetramethylorthosilicate are included for comparison.

Table 2 lists the same precursors by their abbreviations, indicating that those starting with $\mathrm{D}$ are the di-substituted alkoxysilane. The number of reactive groups is indicated, along with the $\mathrm{SiO}_{2}$ content. In those cases with methyl substitutions, the $\mathrm{SiO}_{2}$ content is higher in the di-substituted alkoxysilane, while the $\mathrm{SiO}_{2}$ content is higher in the mono-substituted alkoxysilanes with the phenyl substitutions.

Finally, Fig. 2 has the molecular structures of the precursors. This gives some perspective on the relative size of the substituting groups.

\subsection{Synthesis of melting gels using mono-substituted and di-substituted alkoxysilanes}

In a typical synthesis, the susbstituted alkoxysilanes are used without further purification. Hydrochloric acid and

Table 1 Precursors investigated for melting gels

\begin{tabular}{|c|c|c|c|c|c|}
\hline Chemical name & Formula & Molecular weight & Melting point ${ }^{\circ} \mathrm{C}$ & Boiling point ${ }^{\circ} \mathrm{C}$ & Specific gravity \\
\hline Dimethyldiethoxysilane (DMDES) & $\mathrm{C}_{6} \mathrm{H}_{16} \mathrm{O}_{2} \mathrm{Si}$ & 148.28 & -97 & 114 & 0.865 \\
\hline Methyltriethoxysilane (MTES) & $\mathrm{C}_{7} \mathrm{H}_{18} \mathrm{O}_{3} \mathrm{Si}$ & 178.30 & - & 142 & 0.895 \\
\hline Dimethyldimethoxysilane (DMDMS) & $\mathrm{C}_{4} \mathrm{H}_{12} \mathrm{O}_{2} \mathrm{Si}$ & 120.22 & -80 & 82 & 0.880 \\
\hline Methyltrimethoxysilane (MTMS) & $\mathrm{C}_{4} \mathrm{H}_{12} \mathrm{O}_{3} \mathrm{Si}$ & 136.22 & -78 & 102 & 0.955 \\
\hline Diphenyldiethoxysilane (DPhDES) & $\mathrm{C}_{16} \mathrm{H}_{20} \mathrm{O}_{2} \mathrm{Si}$ & 272.42 & 15 & 167 & 1.033 \\
\hline Phenyltriethoxysilane (PhTES) & $\mathrm{C}_{12} \mathrm{H}_{20} \mathrm{O}_{3} \mathrm{Si}$ & 240.37 & 10 & 112 & 0.996 \\
\hline Diphenydimethoxysilane (DPhDMS) & $\mathrm{C}_{14} \mathrm{H}_{16} \mathrm{O}_{2} \mathrm{Si}$ & 244.36 & 15 & 161 & 1.077 \\
\hline Phenyltrimethoxysilane (PhTMS) & $\mathrm{C}_{9} \mathrm{H}_{14} \mathrm{O}_{3} \mathrm{Si}$ & 198.29 & -25 & 211 & 1.064 \\
\hline Vinyltriethoxysilane (VTES) & $\mathrm{C}_{8} \mathrm{H}_{18} \mathrm{O}_{3} \mathrm{Si}$ & 161.49 & - & 160 & 0.903 \\
\hline Tetraethoxysilane (TEOS) & $\mathrm{C}_{8} \mathrm{H}_{20} \mathrm{O}_{4} \mathrm{Si}$ & 208.33 & -77 & 169 & 0.9335 \\
\hline Tetramethoxysilane (TMOS) & $\mathrm{C}_{4} \mathrm{H}_{12} \mathrm{O}_{4} \mathrm{Si}$ & 152.22 & 4 & 121 & 1.032 \\
\hline
\end{tabular}


Table 2 Silica content and number of reactive groups for precursors

\begin{tabular}{llll}
\hline Precursor & $\begin{array}{l}\text { Molecular } \\
\text { weight }\end{array}$ & $\% \mathrm{SiO}_{2}$ & $\begin{array}{l}\text { Number of } \\
\text { reactive groups }\end{array}$ \\
\hline DMDES & 148.28 & 40.5 & 2 \\
MTES & 178.30 & 33.7 & 3 \\
DMDMS & 120.22 & 50.0 & 2 \\
MTMS & 136.22 & 44.1 & 3 \\
DPhDES & 272.42 & 22.1 & 2 \\
PhTES & 240.37 & 25.0 & 3 \\
DPhDMS & 244.36 & 24.6 & 2 \\
PhTMS & 198.29 & 30.3 & 3 \\
VTES & 161.49 & 37.2 & 3 \\
TEOS & 208.33 & 28.8 & 4 \\
TMOS & 152.22 & 39.5 & 4 \\
\hline
\end{tabular}

ammonia are used as catalysts. Anhydrous ethanol or methanol is the solvent. A total of 24 gels were prepared with the indicated mol\% of mono-substituted and disubstituted alkoxysilanes shown in Fig. 2. As an example, the synthesis pathway for MTES-DMDES system is shown in the flowchart in Fig. 3, and described step-by-step.

The synthesis has three steps. First the water is mixed with hydrochloric acid and with half of the ethanol. The MTES is mixed with the other half of the ethanol separately. Then, the ethanol mixed with MTES is added dropwise to the water solution under continuous stirring. The beaker is covered tightly, and the mixture is stirred at room temperature for $3 \mathrm{~h}$.

In the second step, the di-substituted alkoxysilane DMDES is diluted with ethanol. The DMDES in ethanol
Fig. 2 Schematics of the melting gel precursors
DMDES<smiles>CCO[Si](C)(C)OCC</smiles>

MTES<smiles>CCO[Si](C)(OCC)OCC</smiles>

DMDMS<smiles>CO[Si](C)(C)O[Na]</smiles>

MTMS<smiles>CO[Si](C)(OC)OC</smiles>

DPhDES

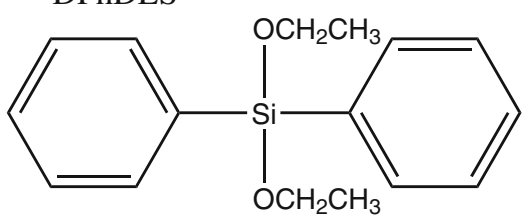

PhTES<smiles>CCO[Si](OCC)(OCC)c1ccccc1</smiles>

DPhDMS

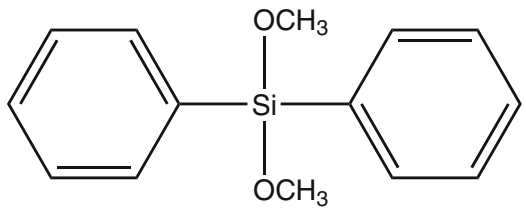

PhTMS<smiles>CO[Si](OC)(OC)c1ccccc1</smiles><smiles>C=C[Si](OCC)(OCC)OCC</smiles><smiles>CCO[Si](OCC)(OCC)OCC</smiles>

TMOS<smiles>CO[Si](OC)(OC)OC</smiles> 
Fig. 3 Typical flowchart of the 3 -step synthesis of melting gels

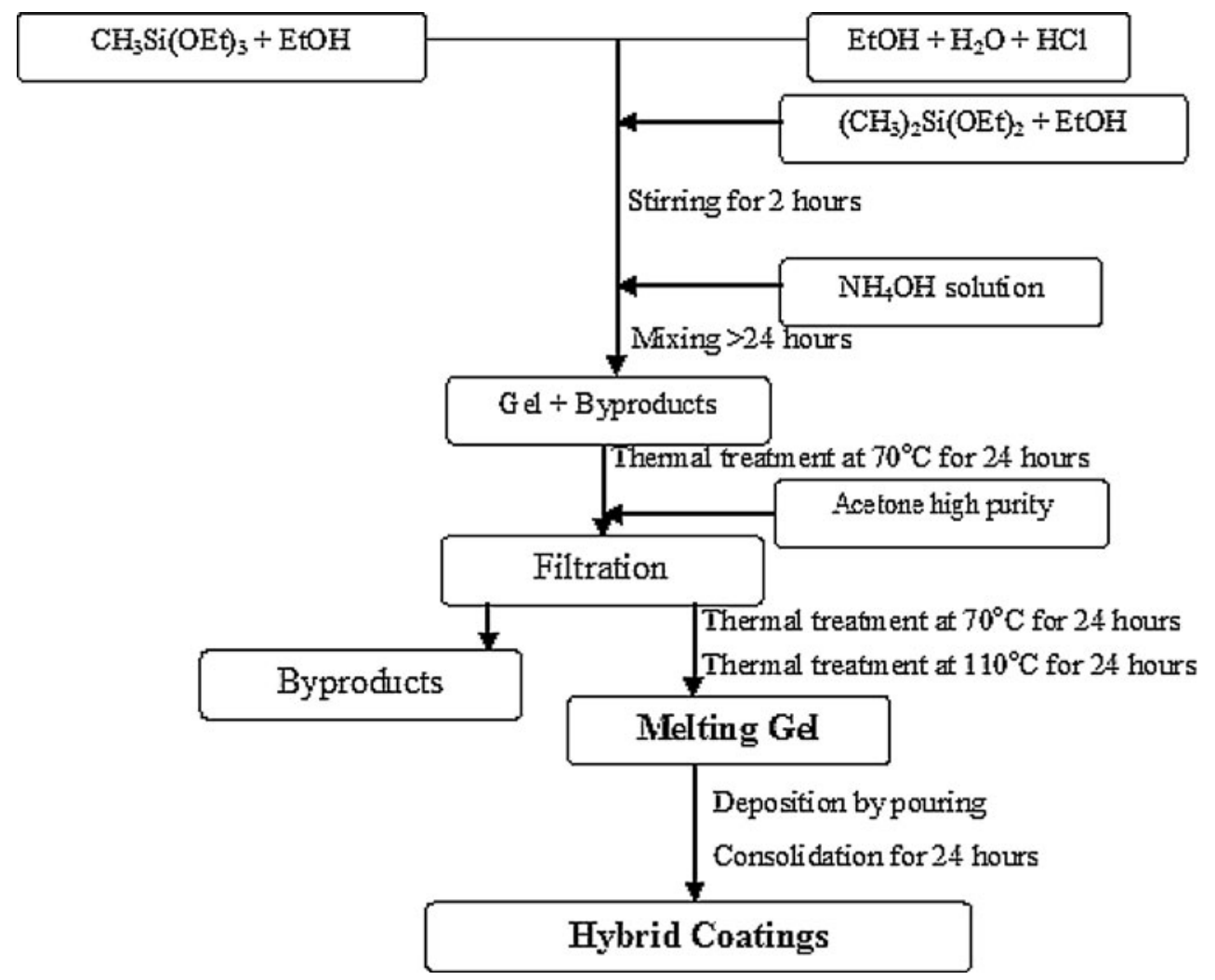

mixture is added dropwise to the mixture from the first step. This solution is kept in a closed beaker at room temperature for another $2 \mathrm{~h}$ of stirring.

In the third step, ammonia is added to the reaction mixture and the solution is stirred for another hour in a closed beaker. Then the clear solution was stirred for $48 \mathrm{~h}$ at room temperature in an open beaker until gelation occurs. The gels are heat treated at $70^{\circ} \mathrm{C}$ overnight in order to remove excess ethanol. During this process, a white powder of ammonium chloride forms on the gels. To remove the ammonium chloride, $10 \mathrm{ml}$ of acetone are added to the samples, followed by removal by vacuum filtration. Again, the gels are heat treated at $70^{\circ} \mathrm{C}$ for $24 \mathrm{~h}$, followed by a last heat treatment at $110^{\circ} \mathrm{C}$ for removal of un-reacted water.

After this heat treatment, the gels are rigid at room temperature. However, when heated above $\sim 110^{\circ} \mathrm{C}$, the gels soften and become fluid, in some cases as fluid as water. To locate the consolidation temperature, samples were subjected to heating and cooling cycles until the minimum temperature was found after which the gels could not be softened. Once the gel had been heated to the consolidation temperature, the behavior was no longer reversible. The consolidation temperatures are listed in Table 3.

The thermal behavior of the hybrid gels before consolidation was studied using differential thermal analysis (Perkin-Elmer DTA-7), thermogravimetric analysis
(Perkin-Elmer TGA-7) and differential scanning calorimetry (DSC TA-Q-2000). DTA and TG were recorded at $5^{\circ} \mathrm{C} /$ min heating rate in the temperature range between 50 and $800^{\circ} \mathrm{C}$ under air flow $(20 \mathrm{ml} / \mathrm{min})$. The total weight loss was recorded and is listed in Table 3. The DSC analyses were recorded using a $5^{\circ} \mathrm{C} / \mathrm{min}$ heating rate between -60 and $400^{\circ} \mathrm{C}$ in nitrogen flow. The glass transition temperatures were determined and are listed in Table 3.

In comparing the methyl substituted melting gels (MTES/DMDES and MTMS/DMDMS) and the phenylsubstituted melting gels (PhTES/DPhDES and PhTMS/ DPhDMS), it is seen that the melting gels cannot be made in the same proportions. The methyl-substituted compositions have more even amounts of the mono- and disubstituted alkoxysilanes, while the phenyl-substituted compositions are a majority of the mono-substituted alkoxysilane, going so far as to have melting gels with $100 \%$ PhTES or PhTMS. When melting gels are made with PhTES and DMDES, the range of compositions is wider and the consolidation temperatures are the highest of any compositions.

\section{Results and discussion}

The weight loss for all gels occurred in two temperature ranges. At lower temperatures between about 150 and 
Table 3 Compositions investigated and glass transition $\left(T_{\mathrm{g}}\right)$ and consolidation temperature $\left(T_{\mathrm{CON}}\right)$

\begin{tabular}{lllll}
\hline $\begin{array}{l}\text { Mono-substituted } \\
(\mathrm{mol} \%)\end{array}$ & $\begin{array}{l}\text { Di-substituted } \\
(\mathrm{mol} \%)\end{array}$ & $T_{\mathrm{g}}{ }^{\circ} \mathrm{C}$ & $T_{\mathrm{CON}}{ }^{\circ} \mathrm{C}$ & $\begin{array}{l}\text { Total } \\
\text { weight } \\
\text { loss } \%\end{array}$ \\
\hline
\end{tabular}

MTES/DMDES

$\begin{array}{llrll}50 & 50 & -56.7 & 160 & 45 \\ 60 & 40 & -37.7 & 155 & 37 \\ 65 & 35 & -18.8 & 150 & 35 \\ 70 & 30 & -6.4 & 145 & 34 \\ 75 & 25 & -0.3 & 135 & 30\end{array}$

MTMS/DMDMS

$\begin{array}{ll}50 & 50 \\ 60 & 40 \\ 65 & 35 \\ 70 & 30\end{array}$

PhTES/DPhDES

$\begin{array}{cr}80 & 20 \\ 83 & 17 \\ 87 & 13 \\ 91 & 9 \\ 100 & 0 \\ \text { PhTMS/DPhDMS } & \end{array}$

$\begin{array}{lrrrr}80 & 20 & 2.6 & 180 & 65 \\ 83 & 17 & 5.0 & 170 & 65 \\ 87 & 13 & 26.1 & 150 & 61 \\ 91 & 9 & 25.4 & 145 & 60 \\ 100 & 0 & 56.6 & 130 & 57\end{array}$

PhTES/DMDES

\begin{tabular}{rrrrr}
50 & 50 & -61.0 & 205 & 65 \\
57 & 43 & -55.7 & 195 & 63 \\
66 & 34 & -29.6 & 180 & 58 \\
74 & 5.6 & 160 & 53 \\
80 & 26 & 2.1 & 150 & 55 \\
\hline
\end{tabular}

$300^{\circ} \mathrm{C}$, the weight loss is attributed to the removal of the ethoxy, methoxy and hydroxyl groups. The second weight loss occurs between about 350 and $500^{\circ} \mathrm{C}$ due to the combustion of the methyl and phenyl groups. For all samples, the differential thermal analysis shows an exothermic peak accompanying the high temperature weight loss, indicating the combustion of the methyl and phenyl groups.

In all cases, the total weight loss increased with increasing amounts of the di-substituted alkoxysilane. Considering the silica content listed in Table 2, the total weight loss is expected to reflect the changes in silica content. Those mixtures with the lowest silica content would show the greatest total weight loss.

The consolidation temperatures listed in Table 3 decrease with a decrease of the amount of di-substituted alkoxysilane, for all systems. This decrease in the consolidation temperature is consistent with the fact that disubstituted alkoxysilanes have only two reactive sites available to create new bonds with the rest of the silica network, while mono-substituted alkoxysilanes have three. Without the mono-substituted alkoxysilane, the di-substituted alkoxysilanes remain liquids after hydrolysis and polycondensations reactions because only linear chains are formed. When mono-substituted alkoxysilanes are mixed with the di-substituted alkoxysilanes, the di-substituted alkoxysilanes act as bridges between the molecular species formed when the mono-substituted alkoxysilanes hydrolyze. In fact, both of the mono-substituted alkoxysilanes PhTES and PhTMS form gels by themselves. The substituted phenyl groups occupy a larger volume than the ethoxy or methoxy groups. When more di-substituted alkoxysilane is present, the high number of phenyl groups creates steric hindrance to the cross-linking process, which leads to an increase of the consolidation temperature. The highest consolidation temperature recorded was for the 50/50 mixture of PhTES and DMDES.

The glass transition temperatures listed in Table 3 show the opposite trend to the consolidation temperature. The $T_{\mathrm{g}}$ values increase with decreasing amount of di-substituted alkoxysilanes. The glass transition is generally thought of as the interval of transition between liquid states and glassy, amorphous states [35]. Put another way, the glass transition is associated with a temperature $T_{\mathrm{g}}$, which is influenced by a number of macroscopic properties, such as viscosity, dielectric constant, and mechanical properties. Using the approach developed for traditional organic polymers and applied to inorganic silica-based polymers [22], the glass transition temperature is considered a measure of the degree of cross-linking in the silica network. In other words, the $T_{\mathrm{g}}$ increases with an increase in the number of oxygen bridges between silicon atoms. The highest $T_{\mathrm{g}}$ values are for samples with only mono-substituted alkoxysilanes, $41.6^{\circ} \mathrm{C}$ for $\mathrm{PhTMS}$ and $33.1^{\circ} \mathrm{C}$ for PhTES. The $T_{\mathrm{g}}$ values for the methoxy-substituted alkoxysilane are higher than the $T_{\mathrm{g}}$ values for the ethoxysubstituted alkoxysilane, given that the methoxy groups are more reactive and achieve a higher degree of polycondensation than for the samples, which contain ethoxy groups.

\section{Conclusions}

Melting gels containing mono-substituted and di-substituted alkoxysilanes were prepared in a three-step synthesis. The hydrochloric acid in the first step acts as a catalyst to allow formation of linear polymer chains. The ammonia in the third step serves to neutralize the hydrochloric acid and 
Fig. 4 Front and cross section images of the thick film prepared with $70 \%$ MTES-30\% DMDES
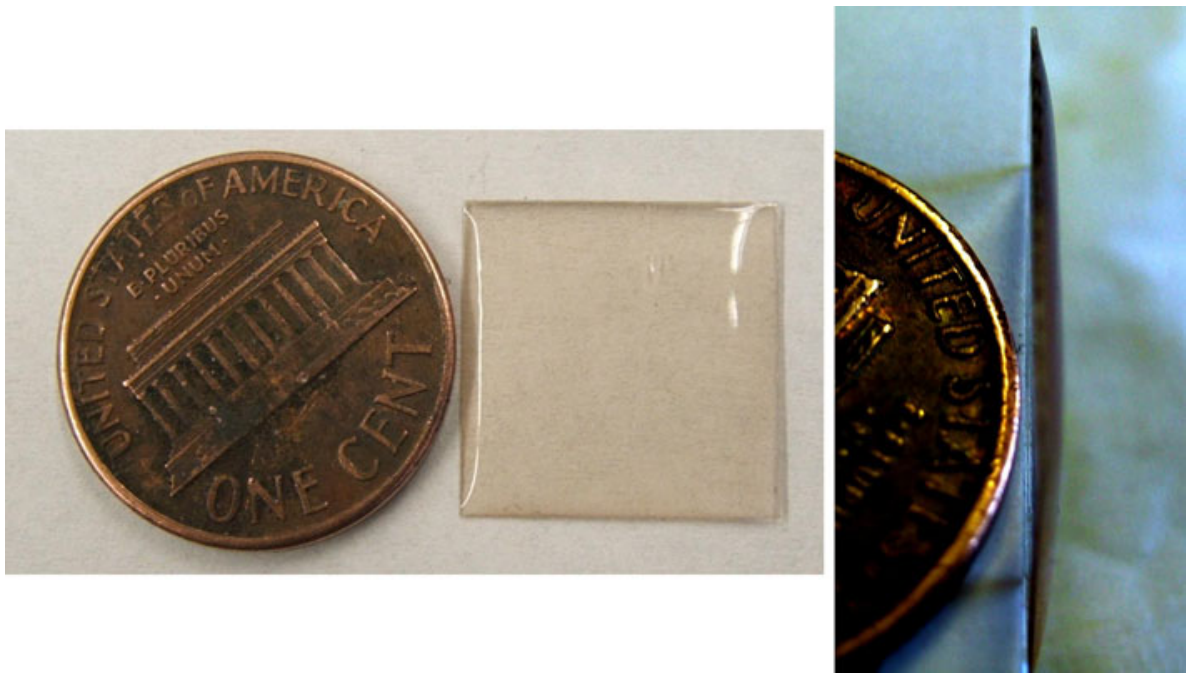

to catalyze further cross-linking between the polymer chains, which leads to gellation. The degree of crosslinking is reflected in the glass transition temperature $T_{\mathrm{g}}$ of the gels before consolidation.

After gellation and heat treatment to remove solvents and water, the gels are rigid. They can be softened by heating to a modest $110^{\circ} \mathrm{C}$. Most of the combinations softened to a viscosity between water and syrup, making pouring easy. When the fluid gel was poured onto a variety of substrates, including glass, mica, silicon, copper and aluminum, the gel adhered well to all surfaces. The thick films were about $1 \mathrm{~mm}$ thick and relatively smooth. A sample is shown in Fig. 4. The films have better than $70 \%$ transmittance of visible light.

One composition that looks promising for low-k dielectrics is the 65\% MTES-35\% DMDES coating, which has a high value of the contact angle $\left(\theta=100^{\circ}\right)$, negligible BET surface area $\left(0.0138 \mathrm{~m}^{2} / \mathrm{g}\right)$ and a low density $\left(1.252 \mathrm{~g} / \mathrm{cm}^{3}\right)$. It appears that this composition is a favorable combination of the mono-substituted and disubstituted alkoxysilanes, which gives a compact network with no accessible surface area. The hardness is about $50 \mathrm{MPa}$ and does not vary with load. Most important, the dielectric constant is about 2.4 at 10 and 1.9 at $100 \mathrm{kHz}$. These values are preliminary data and they will be followed up to determine the suitability of these materials for multilevel interconnect structures.

Acknowledgment Many students have provided valuable data for this review: A. Jackson, J. Doyle, M. Migliaccio, L. Gambino, E. Neubauer, M. Romelus, D. Sobers, A. Growney.

\section{References}

1. Avnir D, Klein LC, Levy D, Schubert U, Wojcik AB (1998) Organo-silica sol-gel materials. In: Rappoport Z, Apeloig Y (eds)
The chemistry of organosilicon compounds, vol 2. Wiley, London, pp 2317-2362

2. Matsuda A, Sasaki T, Hasegawa K, Tatsumisago M, Minami T (2001) Thermal softening behavior and application to transparent thick films of poly(benzylsilsesquioxane) particles prepared by the sol-gel process. J Am Ceram Soc 84:775-780

3. Jitianu A, Doyle J, Amatucci G, Klein LC (2008) Methyl-modified melting gels for hermetic barrier coatings. Proceedings MS\&T 2008 Enabling Surface Coating Systems: Multifunctional Coatings (CD-ROM), Pittsburgh, pp 2171-2182

4. Jitianu A, Amatucci G, Klein LC (2008) Phenyl-substituted siloxane hybrid gels that soften below 140 C. J Am Ceram Soc 92:36-40

5. Jitianu A, Amatucci G, Klein LC (2008) Organic-inorganic solgel thick films for humidity barriers. J Mater Res 23:2084-2090

6. Jitanu A, Klein LC (2009) Sol-gel hybrids for electronic applications: hermetic coatings for microelectronics and energy storage. In: Merhari L (ed) Hybrid nanocomposites for nanotechnology: electronic, optical, magnetic and bio/medical applications. Springer, New York, pp 429-453

7. Hatton BD, Landskron K, Hunks WJ, Bennett MR, Shukaris D, Petrovic DD, Ozin GA (2006) Materials chemistry for low-k materials. Mater Today 9:22-31

8. Tepper T, Berger S (1999) Correlation between microstructure, particle size, dielectric constant, and electrical resistivity of nanosize amorphous $\mathrm{SiO}_{2}$ powder. Nanostruct Mater 11:1081-1089

9. Schmidt H (1984) Organically modified silicates by the sol-gel process. In: Brinker CJ, Clark DE, Ulrich DR (eds) 32 Better ceramics through chemistry, MRS. pp 327-335 (Mat. Res. Soc. Symp. Proc.)

10. Sanchez C (1994) Chemical design of hybrid organic-inorganic materials synthesized via sol-gel. New J Chem 10:1007-1040

11. Gunji T, Iizuka Y, Arimitsu K, Abe Y (2004) Preparation and properties of alkoxy (methyl)silsesquioxanes as coating agents. J Polym Sci Part A Polym Chem 42:3676-3684

12. Ghisleni R, Lucca DA, Wang YQ, Lee J-K, Nastasi M, Dong J, Maher A (2008) Ion irradiation effects on surface mechanical behavior and shrinkage of hybrid sol-gel derived silicate thin films. Nucl Instr Meth Phys Res B266:2433-2456

13. Xu Y, Liu R, Wu D, Sun Y, Gao H, Yuan H, Deng F (2005) Ammonia-catalyzed hydrolysis kinetics of mixture of tetraethoxysilane with methyltriethoxysilane by ${ }^{29} \mathrm{Si} \mathrm{NMR}$. J Non-Cryst Solids 351:2403-2413

14. Orel B, Jese R, Vilcnik A, Lavrencic-Stangar U (2005) Hydrolysis and solvolysis of Methyltriethoxysilane catalyzed with $\mathrm{HCl}$ 
or trifluoroacetic acid: IR spectroscopic and surface energy studies. J Sol-Gel Sci Tech 34:251-265

15. Liu R, Xu Y, Wu D, Sun Y, Gao H, Yuan H, Deng F (2004) Comparative study on hydrolysis kinetics of substituted ethoxysilanes by liquid-state ${ }^{29} \mathrm{Si}-\mathrm{NMR}$. J Non-Cryst Solids 343:61-70

16. Jackson A, Jitianu A, Klein LC (2006) Development of hermetic barrier using vinyl triethoxysilane (VTEOS) and sol-gel processing. Mater Matters 1:11-12

17. Chan Z, Ai'mei L, Xiao Z, Miao F, Juan H, Hongbing Z (2007) Microstructure and properties of ORMOSIL comparing methyl, vinyl, and $\gamma$-glycidoxypropyl-substituted silica. Optic Mater 29:1543-1547

18. Xing W, You B, Wu L (2007) The microstructure and anticorrosive performance of the phytic acid-catalyzed polysilsesquioxane coatings. J Sol-Gel Sci Tech 42:187-195

19. Paulussen S, Rego R, Goossens O, Vangeneugden D, Rose K (2005) Physical and chemical properties of hybrid barrier coatings obtained in an atmospheric pressure dielectric barrier discharge. J Phys D Appl Phys 38:568-575

20. Amberg-Schwab S, Weber U, Burger A, Nique S, Xalter R (2006) Development of the passive and active barrier coatings on the basis of inorganic-organic polymers. Monatshefte Chemie (Chem Monthly) 137:657-666

21. Hass KH, Amberg-Schwab S, Rose K (1999) Functionalization of coating materials based on inorganic-organic polymers. Thin Solid Films 351:198-203

22. Jeong S, Ahn S-J, Moon J (2005) Fabrication of patterned inorganic-organic hybrid film for the optical waveguide by microfluidic lithography. J Am Ceram Soc 88:1003-1036

23. Matsuda A, Matsuno Y, Tatsumisago M, Minami T (1998) Fine patterning and characterization of gel films derived from methyltriethoxysilane and tetraethoxysilane. J Am Ceram Soc 81:2849-2852

24. Skrdla PJ, Saavedra S, Armstrong NR, Mendes SB, Peyghambrian N (1999) Sol-gel based, planar waveguide sensor for water vapor. Anal Chem 71:1332-13337

25. Kwok DY, Neumann AW (1999) Contact angle measurements and contact angle interpretation. Adv Colloid Interface Sci 8:167-249

26. Chen W, Fadeev AY, Hsieh MC, Öner D, Youngblood J, McCarthy TJ (1999) Ultrahydrophobic and ultralyophobic surfaces: some comments and examples. Langmuir 15:3395-3399
27. Castricum HL, Sah A, Mittelmeijer-Hazeleger MC, Huiskes C, ten Elshof JE (2007) Microstructure and enhanced hydrophobicity in methylated $\mathrm{SiO}_{2}$ for molecular separation. J Mat Chem 17:1509-1517

28. Shirtcliffe NJ, McHale G, Newton MI, Perry CC, Roach P (2005) Porous materials show superhydrophobic to superhydrophilic switching. Chem Commun 25:3135-3137

29. Sanchez C, Julian B, Belleville P, Popall M (2005) Application of hybrid organic-inorganic nanocomposites. J Mat Chem 15: 3559-3592

30. Tsuzuki Y, Oikubo Y, Matsuura Y, Itatani K, Koda S (2008) Vacuum ultraviolet irradiation on siliceous coatings on polycarbonate substrates. J Sol-Gel Sci Tech 47:131-139

31. Yu S, Wong TKS, Hu X, Yong MS (2005) Dielectric and mechanical properties of surface modified organosilicate films. J Sol-Gel Sci Tech 35:69-75

32. Ferchichi A, Calas-Etienne S, Smaihi M, Etienne P (2008) Study of mechanical properties of hybrid coatings as a function of their structure using nanoindentation. J Non-Cryst Solids 354:712-716

33. Kakiuchida H, Takahashi M, Tokuda Y, Masai H, Yoko T (2007) Effects of organic groups on structure and viscoelastic properties of organic-inorganic polysiloxane hybrid system. J Phys Chem B111:982-988

34. Masai H, Tokuda Y, Yoko T (2005) Gel-melting method for preparation of organically modified siloxane low-melting glasses. J Mater Res 20:1234-1241

35. Kakiuchida H, Takahashi M, Tokuda Y, Masai H, Kuniyoshi M, Yoko T (2006) Viscoelastic and structural properties of the phenyl-modified polysiloxane system with a three-dimensional structure. J Phys Chem B110:7321-7327

36. Takahashi K, Tadanaga K, Hayashi A, Matsuda A, Tatsumisago M (2007) Effect of phenyltriethoxysilane concentration in starting solutions on thermal properties of polyphenylsilsesquioxane particles prepared by a two-step acid-base catalyzed sol-gel process. J Cer Soc Jpn 115:131-135

37. Takahashi K, Tadanaga K, Matsuda A, Hayashi A, Tatsumisago M (2007) Thermoplastic and thermosetting properties of polyphenylsilsesquioxane particles prepared by two-step acid-base catalyzed sol-gel process. J Sol-Gel Sci Tech 41:217-222 